\section{EL OLIVARES DE MARAÑóN}

\author{
John Elliott \\ Universidad de Oxford \\ john.elliott@history.ox.ac.uk
}

\section{MARAÑÓN'S OLIVARES}

Cómo citar este artículo/ Citation: Elliott, J. (2013). El Olivares de Marañón. Arbor, 189(759):a009. doi: http://dx.doi. org/10.3989/arbor.2013.759n1008

Recibido: 3 septiembre 2012; Aceptado: 1 octubre 2012.

RESUMEN: Este artículo recoge la intervención de John Elliott "El Olivares de Marañón" en la Semana Marañón 2007, "Marañón y la biografía", donde el eminente historiador británico explicó la influencia que El Conde-Duque de Olivares. La pasión de mandar, de Gregorio Marañón ejerció en su interés por el personaje. También se analiza de manera pormenorizada las luces y las sombras del trabajo de Marañón.

PALABRAS CLAVE: Marañón; Conde-Duque; Elliott; historiografía.

La amable invitación de la Fundación Gregorio Marañón para participar en este ciclo de conferencias sobre "Marañón y la biografía" me brinda la oportunidad de reparar algo de la deuda contraída con un hombre, y un libro, cuyo impacto en mi vida y mi carrera profesional sería difícil exagerar. Como he contado a menudo, mi primer encuentro con el Conde-Duque de Olivares fue cuando se me presentó cara a cara en el gran retrato ecuestre de Velázquez en el Museo del Prado durante mi primera visita a España, como estudiante de Cambridge, en 1950. Quedé lo bastante impresionado para querer saber más sobre él, pero no pude encontrar gran cosa de interés en la bibliografía en lengua inglesa que consulté al volver a Gran Bretaña. Pero había despertado mi interés por la historia
Copyright: (C) 2013 CSIC. Este es un artículo de acceso abierto distribuido bajo los términos de la licencia Creative Commons Attribution-Non Commercial (by-nc) Spain 3.0.

ABSTRACT: This article reproduces Sir John Elliott's lecture "The Olivares of Marañón”, given at the Marañón Week in 2007 "Marañón and the biographical genre". The renowned British historian discusses here Gregorio Marañón's book El Conde Duque de Olivares. La Pasión de Mandar (The Count-Duke of Olivares. A Passion for Leading) influenced his interest in Olivares, and analyses the strengths and weaknesses of Marañon's work in detail.

KEYWORDS: Marañón; Count-Duke; Elliott; historiography.

de España, sobre todo por la época del Siglo de Oro. Regresé a la Península dos años más tarde para empezar a aprender español en un curso de verano en Santiago de Compostela, y creo que fue durante esta visita cuando adquirí un ejemplar de la versión abreviada de El Conde-Duque de Olivares de don Gregorio, publicada por Espasa-Calpe en su colección Austral. Como se suele decir, el resto es historia.

Quedé fascinado por el retrato verbal de Olivares pintado por don Gregorio, que podría considerarse una obra complementaria al retrato visual pintado por Don Diego. Cada una de ambas representaciones puede considerarse un estudio sobre el poder. Velázquez, con su poderosa imagen del hombre a caballo, 
capta toda la altiva arrogancia de alguien nacido para mandar. Marañón en su Conde-Duque nos lleva entre bastidores para explorar, a un nivel más íntimo, tanto los imperativos como los costes del poder. El resultado me produjo la impresión de ser una exposición muy reveladora de una personalidad compleja, pero al mismo tiempo me pareció que dejaba algo que desear como un estudio sobre el hombre de estado. Después de todo, se trataba de una de las figuras políticas más importantes de la Europa del siglo XVII, pero sólo veintitrés páginas en un volumen de cuatrocientas estaban dedicadas a los proyectos y medidas políticas de Olivares: trece a su "política exterior y regional" y diez a "la política interior".

Esas páginas ya se habían publicado íntegramente, sin cambios, en la Revista de Occidente bajo el título de "La obra política del Conde-Duque de Olivares", en el año aciago de 1936, poco antes de la aparición del libro. Aunque contienen valiosas ideas y apreciaciones, su misma brevedad significaba que no podían pasar de ser una guía sucinta y sugerente, que apuntaba algunas de las posibilidades que aguardaban a quien tuviera el tiempo y la disposición para seguirlas. En este sentido, representaban tanto un estímulo como un desafío para futuros historiadores y, como un historiador joven y bisoño, fui tan temerario como para aceptar el reto. Era demasiado inmaduro, cuando me embarqué en 1953 en mis investigaciones sobre la carrera política del Conde-Duque, para apreciar la magnitud, y la dificultad, de la tarea que me había propuesto.

Sólo tuve un único y breve encuentro con el Dr. Marañón. Fue en la década de 1950, a mi regreso de los archivos españoles, donde, tras haber buscado sin éxito los papeles del Conde-Duque, había dirigido mi atención al impacto de su política en Cataluña y a la rebelión catalana de 1640. Don Gregorio había sido invitado a Cambridge por Edward Wilson, el catedrático de español. Ya no me acuerdo del tema de su conferencia, aunque creo que era sobre la leyenda de Don Juan; pero guardo un vívido recuerdo de un breve intercambio de palabras con él una vez acabado el acto. Me había intrigado durante mis investigaciones catalanas la figura de aquella "eminencia gris" de Olivares, Jerónimo de Villanueva, el Protonotario de la Corona de Aragón. En unas cuantas ocasiones aparece en la biografía de Marañón sobre el Conde-Duque, sobre todo en relación con el escandaloso asunto de las monjas de San Plácido, acerca del cual Marañón publicó un ensayo en su estudio de Don Juan, publicado en 1940. Esperaba que pudiera proporcionarme más información sobre la misteriosa figura de Villanueva, pero me dijo, muy a su pesar y al mío, que no tenía otros materiales que aquellos que ya había publicado.

Aunque nuestro encuentro fue muy breve, me quedó una vívida impresión personal de Marañón, cuya gravedad me pareció tocada por un aura de melancolía. También me impresionó la lucidez de su exposición y su entrega absoluta a la tarea que le ocupaba. Me di cuenta cabal de este sentido de la dedicación cuando, en 1987, el actual marqués de Marañón puso generosamente a mi disposición el despacho de su abuelo en El Cigarral, y tuve la oportunidad de hojear algunos de los libros y apuntes del Dr. Marañón. Naturalmente había muchas notas y papeles relacionados con el Conde-Duque, entre ellos dos páginas de notas sobre una visita que Marañón hizo en noviembre de 1934 a la última morada de Olivares, en el convento de dominicanas colindante con su palacio en Loeches. "Después del valle del Henares - anotaba- el camino es un desierto... Loeches, plaza de pueblo castellano... La iglesia: muy hermosa. Faltan los cuadros. El mirador del Conde-Duque: emoción al ver la iglesia a través de la celosía y al apoyar la frente en donde él la debió apoyar para llorar sin que le vieran. El Panteón: muy cursi. Hicieron mal en quitarle de la cripta que él se fabricó como sepulcro... . Por la sacristía se pasa al locutorio que parece un fondo de Velázquez. Hablo con la monja: no se le ve: una voz parece que viene del otro mundo... Vio el traslado del cadáver del Conde-Duque desde la cripta al Panteón: estaba entero, robusto, con una banda de general. Al tocarlo, se deshizo en polvo... «Era algo más bajo que el señor doctor", dice la monja... El Palacio... Escalera ancha y revuelta. Cómo debió subir esos escalones al llegar al destierro!".

Cito estas palabras por extenso porque me parece que transmiten una imagen luminosa del propio Marañón: sobre su curiosidad intelectual, su determinación de mover cielo y tierra para recabar información, y su identificación y empatía con el objeto de estudio, sin las cuales es imposible escribir una biografía lograda. La amplitud de las lecturas de Marañón se hacía evidente por doquier al sentarme en su escritorio y mirar los libros y papeles a mi alrededor. Había notas marginales sobre algunos de los documentos en posesión suya, como, por ejemplo, los Fragmentos de la vida de Don Gaspar de Guzmán, por el Conde de la Roca, donde éste habla sobre la muerte de la hija de Olivares, su única descendencia. "Su «último trabajo» (muerte de la hija) le cambió", anota Marañón. También había una carta del 2 de mayo de 1935 escrita por Carmen Jalón, de la Biblioteca Nacional, a quien Marañón se había dirigido para obtener información sobre la documentación de Olivares conservada en el Archivo General de Simancas. "Desde luego -escribía- se le presenta a Vd. material para intimidarse, pero el interés extraordinario de la figura que estudia le anime al trabajo que $\mathrm{Vd}$. enfocará tan sabiamente y como nadie en este personaje especial".

Ciertamente hay "material para intimidarse" en Simancas, pero no incluye tanta documentación pri- 
vada y política de Olivares como uno hubiera podido esperar. Marañón sabía que una cédula real de 1625 concedía al valido permiso para guardar en su posesión y añadir al mayorazgo familiar cualquier libro o papel que le resultara de interés (Marañón, 1952, $434)^{1}$. Pero aunque Marañón trazó la trayectoria posterior de la famosa colección de libros del CondeDuque (Marañón, 1935, 677-692), no parece haberse dado cuenta del hecho de que sus documentos privados y estatales habían ido a parar al archivo de los duques de Alba, y habían sido destruidos por el fuego en el Palacio de Buenavista en 1794 y 1795, lo cual me fulminó como un rayo al enterarme después de unos cuantos meses de búsqueda infructuosa (Duque de Alba, 1953, 19). La pérdida es irreparable.

La circunstancia de que el Dr. Marañón no indagara en la suerte del enorme archivo del Conde-Duque no debe entenderse como una falta de interés por las fuentes originales. Por el contrario, consiguió localizar y leer un número impresionante de documentos del Conde-Duque en persona o relacionados con su vida y época, como se puede constatar con sólo echar un vistazo a la extensa "Bibliografía especial" al final de su libro. En realidad, el listado y el estudio anotado de la documentación que sacó a la luz y consultó es una de sus mayores contribuciones. Su bibliografía proporciona el punto de partida esencial para todo el trabajo posterior sobre Olivares, y recurro a ella constantemente en mi propia búsqueda de información sobre el Conde-Duque y sus tiempos. Además, Marañón no se limitó a listar los documentos. Los leyó y utilizó con talento para explorar distintos aspectos de la personalidad del Conde-Duque y evocar la época en que vivió. Por añadidura, su reproducción, total o parcial, en los apéndices de algunas de las cartas y documentos de estado más importantes de Olivares fue otra contribución útil y me proporcionó un aliciente para publicar con José Francisco de la Peña nuestros dos tomos de Memoriales y cartas del Conde-Duque de Olivares. Todavía espero tener algún día el tiempo y las energías para llevar a cabo una de sus sugerencias relacionadas con la correspondencia del Conde-Duque con el Cardenal Infante. "Estas cartas - escribe- debieran ser publicadas. Su valor para el conocimiento de la historia de aquel reinado y para fijar la verdadera personalidad del Conde-Duque es inapreciable" (Marañón, 1952, 502). Su dictamen sobre la importancia de esa correspondencia es del todo correcta, y su insistencia en la necesidad de su publicación sigue siendo una obligación que la posteridad todavía debe cumplir.

Y en cuanto a esa cantidad intimidatoria de papeles en el Archivo de Simancas, ¿qué se puede decir? Aparte del hecho de que los años 1935-36 no fueron precisamente tiempos propicios para concentrarse en la investigación de archivos, resulta obvio que Marañón, como personaje destacado en la vida pública y con los innumerables compromisos de una brillante carrera médica, no estaba en posición de emprender una investigación a la escala que habría sido necesaria. El gran Fernand Braudel, en una reseña tardía de El conde-Duque de Olivares, publicada en 1947 en la revista histórica francesa Annales, confesó, después de notar que la biografía era la clase de historia más difícil de escribir, que, si hubiera tenido el deseo de estudiar al Conde-Duque, habría retrocedido ante la inmensidad de la tarea. "¿Acaso es posible - proseguía- captar al hombre si no se sigue día a día, durante el transcurso de más de veinte años, el quehacer de alguien que era el patrón del imperio hispánico y no cesaba de escribir, leer y dictar órdenes tratando de frustrar o explotar situaciones a medida que se presentaban? Aun en tal caso, ¿qué se sabe del hombre?" (Braudel, 1947, 354-358).

Incluso si sus propias circunstancias hubieran sido distintas, parece improbable que este sea el tipo de trabajo que Marañón habría estado dispuesto a emprender, aunque hay que decir en honor a la verdad que, en el ocio forzado de sus años de exilio en París, logró producir con su Antonio Pérez una biografía con una base documental mucho más profunda que su Olivares. Pero Marañón no era un historiador profesional, y no se consideraba a sí mismo como tal. Era un médico hasta los tuétanos, pero un médico ampliamente cultivado y de acendrada sensibilidad literaria, que escribía por placer y cuya intensa curiosidad abarcaba tanto el presente como el pasado. Para un historiador profesional hay en su obra evidentes puntos débiles, pero hay que contrabalancearlos con la singularidad de la contribución que le permitió hacer su propia y distintiva educación y formación profesional.

"Yo busco siempre al hombre, aun en el grande hombre", escribió en una ocasión (Laín, 1969, 125). El punto de partida adecuado para cualquier valoración de su Conde-Duque es que Marañón estaba menos interesado en Olivares como político que como hombre. Como él mismo escribe respecto a la "vida pública" del Conde-Duque, "el comentar esa vida... desde un punto de vista estrictamente político, excede los límites de este estudio, cuyo autor es un mero naturalista" (Marañón, 1952, 305). Hay un grado excesivo de modestia en la descripción que Marañón hace de sí mismo como "un mero naturalista". Aunque le separa, como era su intención, del historiador profesional titulado y equipado con conocimientos técnicos, tiende a restarle importancia a su propio interés personal y profesional en el pasado. En parte, sin duda, volver la mirada al pasado constituía una forma de evasión para alguien tan profundamente involucrado en las preocupaciones diarias del presente. Él mismo lo confiesa al escribir en el prólogo a la primera edición 
(1930) de su Ensayo biológico sobre Enrique IV de Castilla y su tiempo: "nada es más grato que proyectar la atención fatigada por el trajín de la vida presente sobre las perspectivas lejanas de la Historia" (Marañón, 1970, 90). Sin embargo, como médico especialista, una parte esencial de sus deberes profesionales era investigar el historial de sus pacientes para lograr comprender mejor su condición presente. En este sentido, hay una afinidad obvia entre las actividades de médicos e historiadores, como él mismo apuntaba al escribir: "la tarea de leer libros y documentos históricos es muy parecida a la de leer historias clínicas" (Laín, 1969, 48).

Con todo, Marañón admite sentir algunos escrúpulos al someter a los muertos a un diagnóstico retrospectivo. El médico en este caso se encuentra a sí mismo en posición de seleccionar arbitrariamente a un paciente, el cual, además, se halla imposibilitado para depositar su confianza en él y separado por "el abismo sin orillas de la eternidad". Los médicos, como confesaba, cometen errores demasiado a menudo al diagnosticar a los vivos. ¡Cuánto más difícil es diagnosticar a los muertos! Aun así, creía que, gracias a avances médicos recientes, la morfología, basada en un retrato o una descripción literaria detallada, hacía posible llevar a cabo un diagnóstico retrospectivo con un grado razonable de precisión. La empresa era en particular legítima ya que, a su parecer, los individuos que cambian el curso de la historia o bien están "francamente enfermos" o bien "atraviesan la vida balanceándose entre la normalidad y la patología" Sin semejantes individuos al filo de la anormalidad, impulsando a sus pueblos hacia adelante, "estaríamos todavía en los linderos de la civilización cavernaria" (Marañón, 1970, 101-102).

Esta visión más bien espantosa del liderazgo y del papel de los dirigentes políticos me parece arraigada en su conciencia de la crisis de su propia época y del país al que pertenecía. Las masas eran propensas a ser moldeadas en manos de sus líderes, que las manipulaban para sus propios propósitos, algunas veces buenos, pero demasiado a menudo malos o erróneos. España, y Europa, estaban al borde de la catástrofe por el tiempo en que él escribía su Conde-Duque y, en mi opinión, algo de este sentimiento de premonición impregna el libro. La España de Olivares, como la de la década de 1930, estaba al borde del abismo, y ese abismo era contemplado por un hombre imbuido con un profundo patriotismo. "Mi vida entera -como escribía a su llegada en América en 1937- es amor a España, servicio de España, sacrificio por España" (Laín, 1969, 178).

Por consiguiente, sospecho que la elección de Olivares como objeto de tratamiento biográfico reflejaba algo más que el interés de un doctor profesional por la vida de una figura política cuyos violentos cambios de humor y repentinos movimientos involuntarios de cabeza, manos y piernas sugerían cierto grado de anormalidad que le convertían en un sujeto interesante para el diagnóstico retrospectivo (Elliott, 1990, 51-52; Marañón, 1952, 122-124). Seguramente también le inspiraba una conciencia de las afinidades entre la España de la década de 1620 y la de 1920, y los peligros que en ambos casos afrontaba su querida patria. En la década de 1620, como en la de 1920, había una élite corrupta, sin ninguna "clase directora" nueva preparada para reemplazarla, y un dirigente que se presentaba como salvador de la patria. También estaba el pueblo español. En el siglo XVII, según lo describía Marañón, el pueblo era ignorante, fanático, supersticioso y exageradamente nacionalista. Pero este pueblo, aunque traicionado por sus dirigentes, era un "pueblo sano bajo la costra" y, en un pasaje con reminiscencias del espíritu de 1898, hoy en día resabios más bien embarazosos, Marañón finalizaba su capítulo sobre "El pueblo" con un elogio de la mujer española, "cuya eficacia de purificación y de conservación de los valores eternos alcanza, en la biología de la hispánica humanidad, una categoría casi milagrosa" (Marañón, 1952, 231). El pueblo sobrevivió la crisis del siglo XVII, así como sobreviviría la del XX. En medio de las tinieblas, brillaba tenue y trémulamente una luz de esperanza. Cualesquiera que sean los defectos de sus dirigentes, "el pueblo intacto, la raza" perdura.

La vida de Olivares, como la del propio Marañón, se caracterizó por el "amor de España, servicio de España, sacrificio por España”. ¿Cómo sucedió entonces que la del Conde-Duque tuviera como resultado conducir a su pueblo al desastre? En un libro dedicado al estudio más de una personalidad que de un político, es inevitable que el peso de la explicación recaiga preponderantemente en el carácter del principal protagonista y sus defectos. Pero hay que decir que a Marañón no le ayudó la historiografía disponible sobre Olivares y su España. Para el trasfondo histórico se basó en gran parte en la obra del historiador británico amateur Martin Hume The Court of Philip IV, publicada en 1907. Hume, aunque concienzudo en la búsqueda de documentos originales, era en el fondo un historiador romántico con una afición fatal por lo anecdótico. Su historia narrativa del reinado de Felipe IV es vívida pero superficial, y se centra en gran medida en la corte, cuya moral y costumbres describe con morbosidad. La corte según Marañón es en esencia la corte según Hume, y su España es la decadente de Hume. No es de extrañar que su presentación del trasfondo histórico de la carrera de Olivares sea el aspecto más flojo del libro. Su retrato de la época, como observaba Braudel en su reseña, no viene a ser más que un telón de fondo pintado a brochazos, un "décor de théatre", más que la fuente de vida que era en realidad. 
Marañón estaba mejor servido a la hora de tratar la carrera política de Olivares, aun cuando se equivocara al afirmar que "la vida pública del Conde-Duque de Olivares, a partir de la fecha de la muerte de Felipe III, hasta veintidós años después, cuando en 1643 termina su privanza, es bien conocida". Utilizaba esta afirmación para justificar la escritura de lo que él mismo llamaba una "historia humana" más que "historia política", (Marañón, 1952, 49) pero este argumento no llega a resistir un examen riguroso. Es cierto que, en líneas generales, se conocía razonablemente bien la trayectoria de la carrera de Olivares, pero en comparación con la historiografía que se había acumulado en torno a otras de las principales figuras políticas del siglo XVII, como por ejemplo a su eterno rival el cardenal Richelieu, la atención prestada a Olivares por parte de los historiadores españoles era sin duda modesta (Elliott, 1984, 12-13). La única contribución realmente seria procedía de la mano de Cánovas del Castillo, cuya propia vida política le impidió explorar la de un gobernante anterior de España con el grado de profundidad que merecía. Pero Marañón, con su acostumbrada generosidad en los agradecimientos, reconoció que Cánovas había ocupado una posición que ofrecía una perspectiva única sobre la carrera de un colega estadista, y notó la evolución de la actitud de Cánovas, desde una hostilidad implacable a una especie de empatía, a medida que se vio pugnando con problemas similares a los que se había enfrentado el Conde-Duque (Marañón, 1952, 411-412).

Cánovas, por tanto, proporcionó al menos a Marañón un esbozo favorable de las intenciones y actividades políticas de Olivares, aunque difícilmente la versión equilibrada que resultaba necesaria si había de llegar a una comprensión plena del hombre mismo. Pero era suficiente para permitirle deslizarse con rapidez sobre los principales hechos de la vida política de Olivares y concentrarse en cambio en el ser humano. Al mismo tiempo, las obras de Cánovas y Hume llamaban la atención sobre la cuestión central de la carrera política del Conde-Duque, la cual Marañón no intentó, ni quiso, evitar. Se trataba de la cuestión de la unidad de España, tan relevante en la década de 1930 como en la de 1630, y como lo es otra vez hoy en día. Tanto Cánovas como Hume habían transcrito al menos parte del más famoso entre todos los documentos de estado de Olivares, su Instrucción secreta, o Gran Memorial, de 1625, y Marañón de manera parecida imprime importantes fragmentos de este escrito como apéndice de su libro (Marañón, 1952, apéndice XVIII).

En este documento, como es bien conocido, Olivares presentaba un plan de acción que había de dar forma a toda la historia de España desde su propia época hasta la nuestra: "Tenga Vuestra Majestad por el negocio más importante de su Monarquía, el hacer- se Rey de España". El rey debería trabajar en secreto para "reducir estos reinos de que se compone España, al estilo y leyes de Castilla". Marañón, como Cánovas, tenía una alta opinión de este manifiesto o "programa de gobierno, cuyas ideas políticas se podrán discutir, pero no su noble intención". Pero es comprensible que, al mismo tiempo, le perturbaran los más maquiavélicos de los métodos propuestos por el CondeDuque para alcanzar lo que Marañón consideraba un fin esencialmente noble: "El acierto de soñar con la unidad enérgica se bastardea aquí con el error de pretender imponer a las demás regiones el modelo obligado de Castilla, error fundamental en un problema como el de los regionalismos, hecho, más que de razones, de susceptibilidades. Hubiera sido más cuerdo crear una forma de unidad en la que no se advirtiese sombra de sometimiento de unas regiones a otras" (Marañón, 1952, 306-307).

Aquí habla Marañón como profundo patriota español, pero la naturaleza de su patriotismo se revela en su tratamiento de la política de Olivares hacia Cataluña. Era un patriotismo arraigado en la aceptación del pluralismo fundamental de España. "Lo incomprensible en el Rey y en su Valido, como en tantos políticos posteriores -escribe- fué el olvidar que las demás regiones que formaban el reino tenían otras obligaciones con el Estado, estipuladas y aceptadas en sus leyes regionales". A Marañón le gustaba describirse a sí mismo como "biólogo", (Laín, 1969, 92) y era con los ojos de un biólogo que veía tanto al CondeDuque como a la España que gobernaba. "En España - proseguía, comparándola con Francia- el problema tenía profundidades biológicas que escapaban y han escapado siempre a las concepciones simplistas de la mayoría de los gobernantes. Los majaderos se ríen cuando se dice que el problema de las regiones es de pura biología; pero es, a pesar de sus risas, tan biológico como su estupidez... La personalidad de las regiones es un hecho tan vivo, que solo la pasión, la malicia, o la necedad lo puede desconocer. Hasta el patriotismo del español es, ante todo, regional... En la vida pública, lo único que une a un español medio con los demás, por encima de las diferencias políticas, religiosas etc., es la regionalidad" (Marañón, 1952, 314-315).

En mi opinión el elemento de determinismo biológico en el enfoque aplicado por Marañón tanto a las colectividades como a los individuos limitaba su capacidad de pensar en términos históricos. Para él, como para muchos de su generación y la precedente, la cuestión de la diversidad regional, que consideraba arraigada en distinciones biológicas, era un problema típicamente español. Pero para un historiador de la Europa moderna constituye un problema universal, que los príncipes y sus ministros intentaban abordar en todas partes al tratar de reforzar el poder de los 
monarcas estrechando los lazos de unión entre sus distintos territorios. Richelieu se metió en problemas en Languedoc y Normandía al procurar imponer un mayor grado de control real. ¿Era Languedoc, con su idiosincrasia lingüística, tan diferente de Cataluña? En la opinión de Marañón, Portugal era una "nación genuina", cuya "separación, impuesta por la realidad de lo étnico... no se hubiera hecho esperar, con Olivares o sin él” (Marañón, 1952, 315 y 317). Pero la Escocia de Jacobo I no era ni más ni menos "nación genuina" que Portugal $y$, una vez hubo ascendido al trono inglés, el rey tuvo que figurar modos de unirla más estrechamente a Inglaterra. Carlos I se enfrentaba a rebeliones en Escocia e Irlanda casi en el mismo tiempo que Felipe IV se enfrentaba a rebeliones en Cataluña y Portugal. Si estas revueltas tuvieron resultados distintos, la explicación parece radicar más en las diferentes políticas, personalidades y contingencias de las dos monarquías que en el reino de la biología.

Pero es, por supuesto, en su tratamiento del protagonista central, Olivares, donde mejor se pueden evaluar las virtudes, y los límites, del enfoque biológico aplicado por Marañón a los fenómenos históricos. Hay que recordar que escribía en una época en que estaba muy en boga la biografía histórica, en particular la fundamentada en el psicoanálisis. Marañón conocía bien la obra de Freud y reconocía su gran importancia, pero albergaba dudas sobre algunos aspectos de la misma y parece haber pensado que tendía a universalizar rasgos psicológicos que pudieran ser peculiares de la Europa central, no necesariamente presentes en otras áreas culturales (Laín Entralgo, 1969, 97-98). En una interesante nota a pie de página en el capítulo inicial de su Enrique $I V$, se refiere favorablemente a la investigación publicada en 1927 por el Dr. Sánchez Banús sobre "La enfermedad y muerte del príncipe don Carlos": "En este certero ensayo justifica el autor la revisión médica de los personajes históricos, diciendo que la Historia hace los caracteres, y los personajes son el núcleo del objeto de la Psiquiatría. Exacto. Pero no sólo la Psiquiatría ha de intervenir en esta labor, sino otras ciencias biológicas, y principalmente - cuando ello es posible - las que estudian la morfología y sus interpretaciones patológicas. Ejemplo de esta valoración de lo somático y lo psíquico para rehacer el retrato de personajes pretéritos, es el admirable libro de Kretschmer, Geniale Menschen. Berlín, 1929" (Marañón, 1970, 102, nota 2).

La psiquiatría, así pues, es sólo una de las herramientas al alcance de aquellos que se aventuran en la "arqueología médica", y la obra de Ernst Kretschmer tendría un papel crucial en la conformación del diagnóstico retrospectivo de Marañón sobre el Conde-Duque. Alemania estaba a la vanguardia de los avances en la psiquiatría europea durante las décadas iniciales del siglo XX, pero los años entre 1914 y 1936 también serían una época dorada para la psiquiatría en España, donde los principales investigadores asimilaban con rapidez los descubrimientos alemanes más recientes ${ }^{2}$. Ernst Kretschmer, catedrático en la Universidad de Marburgo, formaba parte del movimiento en la Alemania de los años 1920 en favor de un enfoque psiquiátrico más amplio, que tuviera en cuenta no solo el cerebro y los órganos sexuales como explicación de los rasgos de personalidad, sino también toda la complexión del cuerpo. Como psiquiatra orgánico combinaba puntos de vista endocrinológicos y psiquiátricos para construir "biotipos" físicos y mentales, con rasgos físicos y mentales hereditarios. Marañón, en realidad el fundador de la endocrinología española, participaba activamente en el diálogo científico entre Alemania y España en las décadas de 1920 y 1930, y en líneas generales le convencía la teoría de Kretschmer sobre la estrecha relación entre personalidad y constitución corporal, aunque nunca sucumbió al determinismo biológico rudimentario y dejaba margen para la acción de otras influencias sobre el desarrollo de la personalidad humana.

La obra de Kretschmer, por lo que he podido averiguar, no ha resistido el paso del tiempo. Identificaba dos tipos distintivos de físico y personalidad: el pícnico, con un temperamento cicloide, y el asténico, con un temperamento esquizoide. Ya en la traducción inglesa de 1936, un apéndice, pese a aceptar las formas clínicas básicas de Kretschmer, afirmaba que investigaciones posteriores habían identificado un gran número de tipos mixtos (Miller, 1970, 272-273). En la década de 1960 un libro sobre la historia de la psicología aseguraba que estudios amplios y rigurosos desde la época de Kretschmer no habían logrado probar la existencia de una estrecha correlación entre las características físicas y la personalidad (Thomson, 1968, 331-332).

Kretschmer, no obstante, estimuló algunas investigaciones útiles, y también proporcionó una clave que ayudaría a Marañón en su tarea de descifrar la compleja personalidad del Conde-Duque. Morfológicamente, Olivares (bajo, fornido y con tendencia a la obesidad) caía de lleno en el grupo pícnico según la clasificación de Kretschmer. Como tipo de personalidad, el pícnico oscila entre la euforia y la depresión, y tiende en caso extremo a ser un maníaco-depresivo. En momentos de exaltación su optimismo le empuja hacia adelante. Se embarca en proyectos grandiosos, su energía no tiene límites, y tampoco su capacidad de trabajo. Luego se hunde en una profunda depresión y experimenta un período de colapso espiritual y psíquico, tan sólo para resurgir con energías renovadas, hasta que el ciclo se vuelve a repetir otra vez. Físicamente, el asténico, en contraste, es, en las propias palabras de Marañón, "enjuto, aguileño, delgado". En términos de personalidad, posee "un espíritu y un 
temperamento frío e irritable, rígido, reconcentrado, de gran vida interior" (Marañón, 1952, 63). El cardenal Richelieu, el antagonista, finalmente victorioso, de Olivares, parecía ajustarse a este tipo a la perfección.

¿En qué medida, cabe preguntarse, esta tipología según las líneas trazadas por Kretschmer favorece nuestra comprensión de la personalidad y las actividades políticas de Olivares, o si se quiere Richelieu? EI interés de Marañón por diferentes tipos de personalidad guiaba su elección de sujetos biográficos. De este modo, encontró una perfecta expresión de timidez en Amiel (1932) y de resentimiento en Tiberio (1939). Olivares, por su parte, podía tomarse como caso representativo de la pasión de mandar, subtítulo de su biografía. Uno de los problemas sobre este tema en particular, como reconocía el mismo Marañón en su introducción, es que "la cantidad de hombres dominados de la pasión de mandar es inmensa" (Marañón, 1952 , 4). Aunque a muchos les consume la pasión por el poder, sólo una proporción relativamente reducida de ellos se encontrará con los medios y las oportunidades parar satisfacerla de lleno. Marañón solo tenía que mirar a su alrededor para ver a algunos de ellos en acción. La Europa de las décadas de 1920 y 1930 era la Europa de los dictadores, y seguramente la ascensión de Mussolini y Hitler le proporcionaba una indicación. ¿Cómo se iba a explicar su surgimiento? Hombres con la pasión de mandar en su forma más extrema llegan a ser dictadores porque se encuentran actuando en un "ambiente social favorable": "es entonces cuando aparece el caudillo, el dictador, el conductor de muchedumbres" (Marañón, 1952, 5). No es sorprendente, pues, ver tratada en su libro la morfología pícnica de Olivares y la morfología asténica de Richelieu bajo el epígrafe "Los dos arquetipos de dictadores" (Marañón, 1952, 63). Los dos estadistas se transforman en dictadores al estilo del siglo XX, cuya sed interior de poder encuentra una conjunción propicia en el "ambiente social favorable".

Aunque Marañón era bien consciente de que el siglo XVII no era el XX, su identificación de Olivares con el dictador del siglo XX me parece tanto ahistórica como desafortunada. El Conde-Duque no tenía ni los mecanismos de control a disposición del dictador moderno, ni sus medios para movilizar a las masas. Nominalmente era el favorito real, el valido, dependiente del favor del monarca para ascender al poder y también conservarlo. Marañón, con razón, otorga gran importancia a la relación personal entre Felipe IV y su valido, la cual es realmente fundamental para comprender la posesión del poder durante veintidós años por parte de Olivares, pero es una relación que considera y analiza desde un punto de vista exclusivamente psicológico. Mientras que el Conde-Duque es dominante y autoritario, el Felipe IV de Marañón es un tipo psicológico muy distinto, el epítome de "la voluntad paralítica" (Marañón, 1952, 232-234).
Hay, por supuesto, un importante elemento de verdad en esta descripción. Felipe IV, a pesar de su inteligencia, se sentía muy poco seguro de sí mismo, sobre todo en sus primeros años en el trono, aunque también podía ser excepcionalmente obstinado, si bien pudiera tratarse de la terquedad propia de los carentes de fuerza de voluntad. Con todo, el retrato de un monarca débil metido en el puño de un favorito dominante no es en ningún sentido una invención de Marañón, aunque éste la dota de matices psicológicos que resultan nuevos. Los embajadores extranjeros en Madrid describían la relación entre el rey y el valido precisamente en tales términos, y a su vez repetían las acusaciones que los enemigos del Conde-Duque continuamente dirigían contra él cuando se esforzaban en derrocarlo. Tras la caída de Olivares del poder en 1643 esas acusaciones no sólo conformaron la percepción del pasado inmediato, sino que además marcaron las pautas de la historiografía del reinado de Felipe IV para las generaciones venideras. El Conde-Duque de Marañón, como antes suyo el de Martin Hume, es el Conde-Duque tirano de los enemigos de Olivares.

Debido a razones perfectamente comprensibles, entre las cuales no es la menor la escasa solidez de la bibliografía histórica de la que se vio obligado a depender, Marañón no muestra conciencia del valimiento como fenómeno histórico, como si fuera meramente personal. La descripción que ofrece de la relación entre el rey y el valido bajo el encabezamiento "Necesidad del valido" proporciona un ejemplo clásico de su enfoque. Tras describir la parálisis de la voluntad real, comenta: "Esta sucinta pintura del alma del Rey, flotando, inerte, como un trozo de madera en los olas, nos explica su conducta en la vida pública y exculpa a su Valido, el Conde-Duque, de la acusación más fuerte que sus contemporáneos le hicieron y transmitieron a los comentadores futuros: el de captar la voluntad del Monarca. No la capta, porque no existía. Fue su privanza y dictadura, como todas las que ha conocido la Historia, un fenómeno de biología pura" (Marañón, 1952, 237).

Se trata de una muestra excelente de su arte de escritor, pero para cualquier historiador actual de la España del siglo XVII semejante explicación resulta claramente inaceptable. Gracias a la obra de una sucesión de historiadores, con José Antonio Maravall y Francisco Tomás y Valiente a la cabeza, disponemos hoy de un conocimiento mucho más profundo del que se tenía en tiempos de Marañón tanto de la teoría de la realeza en la España moderna como de la formación del valimiento como institución política (Maravall, 1955; Tomás y Valiente, 1963; Feros, 2002). Sabemos, por ejemplo, que la maquinaria de gobierno había llegado a ser tan compleja y pesada, y las exigencias sobre el gobierno tan amplias, que incluso un monarca con la mejor de las intenciones ya no podía albergar esperanzas de gobernar sin ayuda. Esto 
originó un espacio para la aparición del valido como primer ministro embrionario, a cargo del despacho de asuntos diarios. Pero la ulterior institucionalización del valimiento chocó con las teorías tradicionales sobre la realeza, cuya expectativa era que el monarca gobernara por sí mismo. El fenómeno se daba a escala europea, y no era exclusivamente hispánico (Elliott, 1984; Brockliss, 1999). Olivares era tanto el beneficiario como la víctima del conflicto resultante entre la teoría y la práctica. Asumía el estilo y las funciones de un primer ministro como respuesta a las necesidades institucionales de gobierno, mientras que todavía tenía que buscar y conservar el favor del monarca ejerciendo las malas artes tradicionalmente atribuidas en la mentalidad popular al privado a la antigua usanza. Ello le exponía inevitablemente a las acusaciones de usurpar el poder real.

Este aspecto institucional del gobierno del CondeDuque se le escapó completamente inadvertido a Marañón. Resulta del todo sorprendente que, cuando describe en la cuarta parte del libro el ambiente donde operaba Olivares y que hizo posible su apropiación y mantenimiento del poder, la administración de una monarquía a escala mundial no aparezca por ninguna parte. En su lugar, el ambiente se limita a "el pueblo", "la familia real", "el hogar", "las mujeres" y, curiosamente, "el hijo bastardo". Es cierto que escribe sobre la tempestuosa relación del Conde-Duque con la nobleza, sobre todo con los grandes, en la sección precedente del libro, pero ¿dónde están los ministros y oficiales que hacían funcionar la maquinaria del gobierno y tenían una parte tan influyente en su vida diaria y en la de la corte? Con excepción de Jerónimo de Villanueva, quien atrajo la atención de Marañón por el escándalo de San Plácido, no aparecen por ningún lado.

De modo parecido, se esperaría encontrar en un estudio sobre el poder alguna explicación no sólo de las disposiciones institucionales en torno al ejercicio del poder, sino también de las estrategias y planes más informales para transformar las intenciones en acción. El patronazgo era un arma decisiva en el arsenal del Conde-Duque, y era a través de la manipulación de los vínculos de patronazgo y clientela en una sociedad basada en redes familiares y sistemas de dependencia de gran extensión que operaban los estadistas del siglo XVII. Olivares no era ninguna excepción. Dependía en gran medida de sus parientes de la conexión familiar Guzmán-Zúñiga en la consecución de apoyo para consolidar su control del poder, mientras que al mismo tiempo formaba un impresionante grupo de hechuras (los favoritos del favorito), de quienes podía depender para el cumplimiento de sus órdenes. Para alguien que operaba en una sociedad dividida en facciones, movida por rivalidades familiares, y forzado a trabajar con una pesada burocracia opuesta por naturaleza a cualquier iniciativa que amenazara romper con la tradición, ésta era la única forma de sacar las cosas adelante. Marañón realizó una valiosa contribución al resucitar las figuras de algunos de los parientes más próximos del Conde-Duque, como el conde de Monterrey, el marqués de Leganés y el duque de Medina de las Torres, pero los considera simplemente como personalidades y no da señal de apreciar la parte que desempeñaron en el funcionamiento de su sistema de gobierno. Tampoco presta ninguna atención al grupo muy cohesionado de hechuras, sin cuya ayuda habría sido incapaz de poner en práctica su política.

La falta de contextualización del Conde-Duque dentro de las estructuras institucionales, sociales y políticas en las que se veía obligado a operar implica que obtenemos un retrato vívido pero en exceso personalizado de un hombre obsesionado por la pasión de mandar. Los impulsos son los del dictador; los errores surgen de rasgos de personalidad. Si Marañón hubiera tenido la oportunidad de leer detenidamente las consultas de los diversos consejos, sobre todo las del Consejo de Estado, creo que se habría visto obligado a modificar su retrato de un hombre que actuaba según los dictados de su propio temperamento caprichoso en lo que era en gran parte un vacío político. Tomemos, por ejemplo, el tratamiento de Marañón de la decisión tomada por Madrid en la primavera de 1621 de no renovar la Tregua de los Doce Años con la República Holandesa. Marañón la describe como el primero de los "yerros" de la "gestión política" de Olivares (Marañón, 1952, 308). Es cierto que Olivares se oponía firmemente a la continuación de la tregua, pero la decisión final de Madrid se tomó tres semanas después del inicio del nuevo reinado, en una época en que ni siquiera era miembro del Consejo de Estado. Tampoco resultaría posible apreciar a partir de la explicación de Marañón que esta decisión había sido precedida por dos años de debate en los diversos consejos, y que había fuertes argumentos en favor, así como en contra, la reanudación de la guerra con los holandeses, quienes por su parte también estaban volviéndose en contra de la perpetuación de la tregua (Elliott, 1990, 82-86).

El retrato de Olivares por Marañón como fundamentalmente un hombre-orquesta significa que aquí, como en otras partes, su explicación de las intenciones y acciones políticas del Conde-Duque sufre de su incapacidad de relacionarlas con la mentalidad y las actitudes de la élite dirigente de que formaba parte. Lo presenta como un "héroe de la visión española de Felipe II", y como el "ejecutor, en mayor medida que el mismo Monarca, del espíritu de los Austrias", quienes se dejaban llevar por sus "sueños de imperialismo y de monopolio de la catolicidad". "Además - prosigue- sobre esta profesión política, [Olivares estaba] dotado de un carácter imperativo y horro de matices, cuyas consecuencias no se hicieron esperar" (Marañón, 1952, 306). 
Es realmente cierto que Olivares se veía a sí mismo como una vuelta a la gran tradición de Felipe II después de lo que consideraba habían sido los desastres y humillaciones del reinado de Felipe III, pero no creo que sea correcto describir ni sus postulados ni su conducta en términos tan simplistas. Pertenecía a una élite dirigente muy consciente de las cargas y obligaciones que implicaba sostener un imperio a escala mundial. En el siglo XVII esa élite pensaba no en términos de expansión imperial, sino de la conservación de los territorios lejanos de la monarquía contra una multitud de enemigos. También pensaba en términos de reputación, el prestigio que todo estadista del siglo XVII sabía que era un arma esencial en el arsenal del poder real. Reputación es una palabra que aparece una y otra vez en los debates sobre directrices políticas del Consejo de Estado. El pensamiento de Olivares, por tanto, coincidía con el de la élite dirigente española en su conjunto, en la medida en que luchaba por conservar la posición de España y su monarca sin merma de reputación en un mundo hostil. Los desacuerdos en el seno de la élite eran acerca de las tácticas más que de los objetivos y, lejos de ser "horro de matices", el Conde-Duque era capaz de tomar iniciativas tácticas, tales como enviar subsidios a herejes cuando convenía a sus propios propósitos (Elliott, 1984, 168-170), las cuales atestiguan la perspicacia política de un hombre dotado para considerar al mundo en términos que distan mucho de ser exclusivamente maniqueos.

¿Hasta qué punto, pues, se sostiene todavía el retrato de Marañón a la luz de las investigaciones históricas de los últimos setenta años? Como he intentado aclarar, me parece que hay serias deficiencias en su tratamiento del Conde-Duque como estadista, aunque creo que sería difícil discrepar de su descripción general de Olivares como político con nobles ambiciones para "una completa renovación del país" (Marañón, $1952,309)$, pero cuyas directrices terminaron en desastre. De hecho, esta es la imagen que intenté matizar y desarrollar en mi biografía política del Conde-Duque. Por lo que respecta a su retrato de Olivares como hombre, creo que sigue siendo incomparable, aunque me parece que debe mucho más al mismo Marañón que a las teorías de Ernst Kretschmer. Su descripción de los principales rasgos de la extravagante personalidad del Conde-Duque me resulta convincente, y los numerosos relatos y caracterizaciones escritas por sus contemporáneos la confirman ampliamente.

Al mismo tiempo, debo confesar que encuentro la interpretación fundamentalmente biológica de la personalidad del Conde-Duque de Marañón en exceso reduccionista. No estoy convencido de que haya mucha correlación entre la complexión del Conde-Duque y los modos en que hacía realidad su "pasión de mandar", y tampoco creo que Olivares fuera tan prisionero del mecanismo biológico como Marañón parece indicar. No es necesario recurrir a interpretaciones biológicas o psicológicas para explicar la alternancia entre la euforia y la depresión experimentada por un hombre que constantemente recibía noticias de todas las partes del mundo, a veces buenas pero en general malas, pues los informes de una victoria gloriosa en una parte del planeta eran desplazados con rapidez por informes de derrota en otra, o quedaban ensombrecidos de repente por las nuevas de la pérdida de la flota de la plata de las Indias de la que dependía la campaña del año siguiente. Es perfectamente posible que las reacciones de Olivares a la cara cambiante de la fortuna fueran más extremas de lo que se podría esperar normalmente, pero merece la pena recordar que el asténico Richelieu, al igual que el pícnico Olivares, era propenso a violentos arrebatos de ira, y estaba sometido a tanta tensión que sufría colapsos físicos en momentos de depresión (Elliott, 1984, 26-27). Los dos estadistas trabajaban hasta el límite de sus fuerzas, y no es extraño que en momentos de agotamiento mental y físico no desearan nada más que dejar sus tareas y desaparecer de la vista del público.

También es difícil saber la importancia que hay que dar a las expresiones de melancolía más morbosas de esas "cartas lúgubres" que Olivares escribía tan a menudo, llenas de giros al estilo de "deseo más la muerte que servir un día más" (Marañón, 1952, 8-83). La religiosidad del Conde-Duque, su obsesión por la muerte y la salvación, eran características de la espiritualidad barroca, y no está claro si sus reacciones ante los desastres diferían de modo significativo de las de sus contemporáneos. Pero incluso si aceptamos la posibilidad de una religiosidad extravagante, sobre todo tras la muerte de su hija María, me parece que Marañón no captó la medida en que fuerzas compensatorias ponían freno a los impulsos biológicos. En los últimos años hemos tenido una mayor conciencia de la influencia de las doctrinas neo-estoicas sobre la generación de Olivares, según eran difundidas por los escritos de Justo Lipsio (Oestreich, 1982). El mensaje de Lipsio era de fortaleza cristiana ante la adversidad, y hay buenos motivos para creer que el Conde-Duque dio forma a su vida y mantuvo bajo control sus instintos naturales conscientemente mediante la puesta en práctica de la autodisciplina estricta que constituye el meollo de ese mensaje (Elliott, 1990, 286-287).

Así pues, no creo que sea injusto decir que, aunque Marañón describe admirablemente muchos de los rasgos más distintivos de la personalidad del CondeDuque, de manera como no habían sido captados anteriormente, ni lo han sido desde entonces, no logró llegar a darnos un retrato del todo acabado de ese hombre extraordinario. La misma organización del libro, además, tiende a perjudicar la percepción de Olivares en su integridad, y esto es particularmente cierto de la importante tercera parte, dedicada a Olivares como persona. Aquí tenemos una disección del 
hombre, capítulo a capítulo, cada uno de ellos destinado a ilustrar algún aspecto de Olivares y su carácter: "La figura", "El humor", "La lucha contra los grandes", "Los impulsos", "Los defectos", "El intelectual”, "Las virtudes", etcétera. Por separado, muchos de esos capítulos son en extremo esclarecedores, pero el efecto de tal punto de vista clínico, al menos para este lector, es dejar a Olivares desmembrado sobre la mesa de operaciones, como si, una vez finalizada la disección, el médico responsable de la operación no estuviera del todo seguro de cómo montarlo de nuevo.

Sin embargo, a pesar de lo que me parecen defectos importantes en el libro, me encontré volviendo a él una y otra vez al escribir mi propio estudio sobre la carrera política de Olivares. No hay que ir muy lejos para encontrar las razones. Por fragmentario que fuera el tratamiento de la vida y carrera del Conde-Duque, los mismos fragmentos están llenos de vida e interés. Son una prueba de la medida del éxito de Marañón a la hora de reunir una gran variedad de fuentes contemporáneas, muchas de los cuales eran desconocidas o ignoradas hasta que logró sacarlas a la luz, y también atestiguan la aguda inteligencia con la que analizó los testimonios ante él. Algunos de sus capítulos, en especial los que tratan sobre la vida intelectual del CondeDuque, su apasionada bibliofilia y su relación personal con poetas, dramaturgos y pintores (Quevedo, Calderón de la Barca, Rubens, Velázquez y muchos otros) abrió vías de investigación que todavía no se han explorado por completo. Si el tratamiento de Marañón de la actividad política del Conde-Duque fue superficial, nada importante se ha añadido posteriormente a su dramático relato de la caída de Olivares del poder y los trágicos últimos años de su vida. En conclusión, su logro sigue siendo impresionante, y el Olivares de Marañón conservará siempre su lugar en la bibliografía histórica. Aunque, como biografía histórica, el libro es sólo un éxito parcial, no se trata de algo que pueda sorprender o se deba reprochar. Como Braudel escribía en su reseña, "Olivares es un cortejo de personas y requiere un cortejo de explicaciones". No se puede esperar de ningún biógrafo, ni siquiera de uno con el talento único del Dr. Marañón, que abarque todo ese cortejo de personas y las explique todas.

(Traducción de Marta Balcells, revisada por el autor)

\section{NOTAS}

1 Todas las citas que se reproducen en este artículo están tomadas de la versión, revisada y final publicada por $\mathrm{Ma}$ rañón en 1952, si bien, la primera edición es de 1936.

\section{BIBLIOGRAFÍA}

Braudel, F. (1947). Annales, 2, Paris.

Brockliss, L. W. B. (1999). El mundo del valido. Madrid: Taurus.

Duque de Alba (1953). El archivo de la Casa de Alba. Madrid.

Elliott, J. H. (1990)- El Conde-Duque de Olivares. El político en una época de decadencia. Barcelona: Crítica.

Elliott, J. H. (1984). Richelieu y Olivares. Barcelona: Crítica.

Feros, A. (2002). El Duque de Lerma. Realeza y privanza en la España de Felipe III Madrid: Marcial Pons.

Hume, M. (1907). The Court of Philip IV. Spain in Decadence. Londres (nueva edición, 1928).
2 Para esta observación y las siguientes, véase Richards, Michael (2004): "Spanish Psychiatry c.1900-1945: Constitutional Theory, Eugenics, and the Nation", Bulletin of Spanish Studies, 81, pp. 823-848. Estoy en deuda con el Dr. James Amelang por llamar mi atención sobre este artículo.
Laín Entralgo, P. (1969). Gregorio Marañón. Vida, obra y persona. Madrid: Espasa Calpe.

Marañón, G. (1952). El Conde-Duque de Olivares (La pasión de mandar). Madrid: Espasa Calpe (tercera ed., 1a de 1936).

Marañón, G. (1935). La biblioteca del CondeDuque de Olivares. Madrid, Boletín de la Real Academia de la Historia, no 107.

Marañón, G. (1970). Ensayo biológico sobre Enrique IV de Castilla y su tiempo. En Obras completas, tomo V, Madrid: Espasa Calpe.

Maravall, J. A. (1955). La Philosophie politique espagnole auXVIle siècle. París: Vrin.

Miller, E. (1970). Apéndice a E. Kretschmer
Physique and Character (2a. ed.), Nueva York.

Oestreich, G. (1982). Neostoicism and the Early Modern State. Cambridge: Cambridge University Press.

Richards, M. (2004). Spanish Psychiatry c.1900-1945: Constitutional Theory, Eugenics, and the Nation. Bulletin of Spanish Studies, 81, University of Glasgow.

Thomson, R. (1968). The Pelican History of Psychology. Londres.

Tomás Valiente, F. (1963). Los validos en la monarquía española del siglo XVII Madrid. IEP. 